\title{
VARIAÇÃO LINGUÍSTICA E ENSINO: A CONTRIBUIÇÃO DOS ENCONTROS DE SOCIOLINGUÍSTICA
}

\section{LINGUISTIC VARIATION AND EDUCATION: THE CONTRIBUTION OF SOCIOLINGUISTIC SEMINARS}

Norma da Silva Lopes ${ }^{1}$ Cristina dos Santos Carvalho ${ }^{2}$ Raquel Meister Ko. Freitag ${ }^{3}$

A Sociolinguística como uma ciência autônoma se inicia na década de 1960, nos Estados Unidos e tem como precursor o linguista William Labov, que realizou, individualmente ou em parceria com outros estudiosos, trabalhos sobre a relação entre língua (no caso, a língua inglesa e suas variedades) e contexto social, destacando fundamentos teóricos e metodológicos essenciais a essa nova área de investigação linguística (WEINREICH; LABOV; HERZOG, 2006 [1968]; LABOV 2008 [1972, entre outros).

O termo Sociolinguística já suscita uma questão teórico-metodológica no que se refere aos possíveis modos de estudo da língua e a (des)consideração do seu componente social. O próprio Labov explicitou a sua resistência ao uso desse termo "já que ele implica que pode haver uma teoria ou prática linguística bem sucedida que não é social" (LABOV 2008 [1972, p, 13). Nesse caso, o emprego do rótulo Sociolinguística pode ser entendido como uma forma de questionamento ou crítica à prática de análise linguística dissociada de aspectos históricos e sociais que vigorava no século XX.

\footnotetext{
1 Professora Plena da Universidade do Estado da Bahia, Permanente do Programa de Pós-Graduação em Estudo de Linguagens (PPGEL/UNEB). Email: nlopes58@gamail.com

2 Professora Titular da Universidade do Estado da Bahia e docente permanente do Programa de Pós-Graduação em Estudo de Linguagens (PPGEL). E-mail: crystycarvalho@yahoo.com.br.

3 Professora do Departamento de Letras Vernáculas, do Programa de Pós-Graduação em Letras e do Programa de Pós-Graduação em Educação da Universidade Federal de Sergipe. E-mail: rkofreitag@uol.com.br
} 
Os estudos sociolinguísticos, dessa forma, rejeitam a visão de homogeneidade linguística defendida por abordagens imanentes da língua (estruturalista e gerativista) e assumem a unidade e a diversidade como características das línguas humanas que não são excludentes. Partem do princípio, então, de que não existe incompatibilidade entre as noções de sistema linguístico, estrutura, de um lado, e diversidade ou heterogeneidade ou variabilidade linguística, do outro. Assim, nessa nova perspectiva teórica, considera-se a língua como um sistema de regras categóricas e variáveis:

Mesmo que a princípio se possa pensar que heterogeneidade implica ausência de regras, a Sociolinguística vê a língua como um objeto dotado de heterogeneidade estruturada - logo, há regras, sim. Decorre daí que, enquanto a língua concebida como sistema homogêneo contém somente regras categóricas, que sempre se aplicam da mesma maneira, a língua concebida como sistema heterogêneo comporta, ao lado de regras categóricas, também regras variáveis, condicionadas por fatores tanto do contexto linguístico como do contexto extralinguístico, (COELHO et al., 2018, p. 59),

No Brasil, no final da década de 1970, Anthony Naro e seu grupo, na Universidade Federal do Rio de Janeiro, inauguram os estudos sociolinguísticos no país, com a descrição da variação linguística no Rio de Janeiro, inicialmente com os dados do Mobral. Como desdobramento, na década de 1980, o Projeto Censo é implementado e instaura a constituição de bancos de dados de entrevistas sociolinguísticas, posteriormente abarcado pelo Programa de Estudos sobre os Usos da Língua (PEUL) e referência para a execução dos demais empreendimentos sociolinguísticos no país.

A pesquisa sociolinguística produzida no Rio de Janeiro fez surgirem, no Brasil, estudos sobre o português brasileiro e suas diversas variedades no nosso território. Sobre essa questão, Martins e Abraçado (2015, p. 7) mostram que tem sido realizado um vasto mapeamento sociolinguístico do português brasileiro, "que consolida resultados de importantes estudos em diversas regiões do país sobre processos de variação e/ou mudança linguísticas envolvendo (a) fenômenos fonético-fonológicos [...]; e (b) fenômenos morfossintáticos.

No que diz respeito à região Nordeste do território brasileiro, o empreendimento sociolinguístico tem contribuído para a descrição de normas linguísticas nos diferentes estados dessa região, em projetos de colaboração com foco local e/ou regional. E é nessa perspectiva que contextualizamos o Encontro de Sociolinguística, em sua oitava edição. Com o intuito de preencher, ainda que de forma tímida, uma lacuna na Bahia e, mais especificamente, em Salvador quanto a eventos nesse campo do conhecimento, o Encontro de Sociolinguística nasceu como evento local na Universidade do Estado da Bahia (UNEB), no Programa de Pós-Graduação de Estudo de Linguagens (PPGEL), idealizado pela professora Norma Lopes, pesquisadora dos estudos da variação e da sócio-história do Português Brasileiro. Teve sua primeira edição em 2011, como uma das atividades do Projeto de Pesquisa Linguagem na Cidade, com o fomento da Fundação de Amparo de Amparo à Pesquisa no Estado da Bahia (FAPESB), edital PRO-PESQUISA 011/2011, sob a coordenação das professoras Norma Lopes, Lígia Pellon e Cristina Carvalho.

Desde a sua idealização, o evento teve como objetivo congregar pesquisadores da área de Sociolinguística, de diferentes Instituições de Ensino Superior, para que houvesse uma discussão e socialização dos resultados dos trabalhos produzidos nessa área. Nesse sentido, não se pode perder de 
vista a importância de realização de eventos para a fixação e/ou consolidação de uma área de conhecimento. E foi justamente isso que aconteceu no em relação à Sociolinguística quando, em 1964, na Universidade da Califórnia em Los Angeles (UCLA), ocorreu um congresso organizado por William Bright, do qual participaram nomes como John Gumperz, William Labov, Dell Hymes, John Fisher, pesquisadores, os quais, utilizando-se aqui as palavras de Alkmim (2001, p. 28), "se constituiriam, posteriormente, em referências clássicas na tradição de estudos voltados para a questão da relação entre linguagem e sociedade". Tal congresso se tornou um marco para o estabelecimento da Sociolinguística como área da Linguística.

Ademais, dos trabalhos apresentados nesse congresso da UCLA, resultou a publicação de um livro intitulado Sociolinguistics (Sociolinguística). Em um dos textos desse livro, definem-se objeto de estudo (a diversidade linguística), tarefa da sociolinguística ("demonstrar a co-variação sistemática das variações linguística e social)" (BRIGHT, 1974, p. 17) e dimensões possíveis dos estudos sociolinguísticos (identidade social do falante ou do ouvinte, contexto, a maneira como as pessoas usam as línguas e suas crenças sobre seu comportamento linguístico e dos demais, a da aplicação e a feita pelo planejador linguístico, entre outras). Nos termos do autor, quando duas ou mais dimensões se interseccionam, já há um objeto de estudo sociolinguístico.

Sobre as áreas de interesse da Sociolinguística, Mollica (2004) menciona, além dos processos de variação e mudança linguísticas, questões referentes ao contato entre as línguas, multilinguismo e surgimento e extinção linguísticas. Embora esses temas continuem ainda atuais, novas demandas surgiram na contemporaneidade. A esse respeito, Mollica e Ferrarezi Junior (2016) ressaltam:

\footnotetext{
Com os desafios do mundo globalizado, em que as sociedades se conectam de forma nunca antes possível, as relações sociais e a intermediação das línguas naturais exercem função determinante nas sociedades do mundo. Tornaram-se, desse modo, indispensáveis como objeto de análise, em ciência em ebulição, "fervente" nas mãos de especialistas. [...].
}

A Sociolinguística se constitui de permanente repensar-se e redescobrir-se desde a descoberta da possibilidade de se estudar sistematicamente a variação e a mudança linguísticas. Os estudos avançados sobre a aquisição da heterogeneidade estruturada, os voltados para a origem e as consequências linguísticas provenientes do contato em redes, as análises sobre indivíduos e línguas isolados, tanto quanto as investigações acerca dos princípios da relação entre língua e cognição, reúnem um legado sob o rótulo maior que consiste em um universo de desafios, de questões a resolver e de inexplorados campos a desbravar. Sem dúvida, solidifica-se a Sociolinguística como rico espaço para a existência de iniciativas e pesquisas inovadoras [...]. (MOLLICA; FERRAREZI JUNIOR, 2016, p. 10-11).

Para o atendimento a essas novas demandas e explicação de alguns fenômenos linguísticos, como explicitado em Martins e Abraçado (2015) com discussões teóricas e resultados de trabalhos de pesquisadores brasileiros, a Sociolinguística tem buscado interfaces com distintas teorias linguísticas: por exemplo, (i) com o Funcionalismo linguístico de vertente norte-americana, com ênfase na abordagem da gramaticalização e sua relação com o processo de variação linguística (o que tem sido denominado de Sociofuncionalismo) e (ii) com a Linguística Cognitiva, resgatando-se a relação entre variação e cognição 
(o que tem sido designado de Sociolinguística Cognitiva). Outro exemplo de "casamento" teórico tem sido evidenciado entre a Sociolinguística e a Dialectogia, no que tem sido chamado de pesquisas geossolinguísticas.

Outro desafio que tem sido imposto à Sociolinguística tem a ver com as implicações dos seus postulados sobre variação e mudança linguísticas para o ensino de língua materna, o que motivou o surgimento de uma nova vertente dos estudos sociolinguísticos na dimensão de aplicação à educação, a chamada Sociolinguística Educacional (BORTONI-RICARDO, 2004, 2005). Como bem lembra BortoniRicardo (2017), desde os primórdios da Sociolinguística, já havia uma preocupação com questões atinentes à relação entre variação linguística e desempenho escolar de estudantes:

\begin{abstract}
Na sua infância, a pesquisa sociolinguística foi motivada pela constatação de que crianças oriundas de grupos linguísticos minoritários apresentavam desempenho escolar muito inferior ao das crianças provenientes de classe média e classe alta. [...] $\mathrm{Na}$ década de 1960, quando os primeiros sociolinguistas buscavam no repertório linguístico das crianças as explicações para o seu melhor ou pior ajustamento à cultura escolar, ainda pouco se discutia o impacto da cultura letrada sobre grupos sociais ou nacionais.
\end{abstract}

Liderados por William Labov, os sociolinguistas pioneiros, nos Estados Unidos, desenvolveram intensas análises contrastivas entre a variedade do inglês que era a língua materna dos alunos em questão e o chamado inglês padrão, falado e ensinado na escola (BORTONI-RICARDO, 2017, p. 12-13).

No que concerne ao cenário educacional do Brasil, Martins, Vieira e Tavares (2014, p. 7) enfatizam "a necessidade de um ensino de português pautado na realidade sociolinguística brasileira, em que convivem diferentes normas e variedades regionais, sociais e estilísticas". Os autores ainda pontuam algumas questões relacionadas à variação e ensino que consideram relevantes para o professor em sala de aula:

\begin{abstract}
(1) Como articular a diversidade linguística com o ensino de português? Ou, ainda. Qual (ou quais) norma(s) ensinar? (2) Qual a influência dos processos fonético-fonológicos da modalidade oral do português brasileiro na aquisição da escrita? Como lidar na sala de aula com essa influência? (3) Qual o papel da ação escolar sobre o processo de aquisição da modalidade escrita do português brasileiro, evidenciada, por exemplo, na exigência de emprego de determinadas estruturas morfossintáticas incomuns na fala espontânea? (4) Qual o tratamento dispensado à variação linguística no Programa nacional do Livro Didático (PNLD), considerando a superficialidade com que ela é, ainda, abordada nos manuais didáticos? E (5) Qual o papel da escola na construção de crenças e atitudes positivas dos alunos em relação aos usos que eles costumam fazer do português brasileiro? (MARTINS, VIEIRA; TAVARES, 2014, p. 7).
\end{abstract}

Em alinhamento com antigas e novas demandas da área, as oito edições do Encontro de Sociolinguística sempre estiveram em sintonia com a agenda dos estudos sociolinguísticos brasileiros, de suas vertentes e de suas interfaces. Ano a ano, a capilaridade do evento foi aumentando, de modo a constituir uma rede de contatos (FREITAG; SILVA; ARAUJO, 2018), com uma agenda de discussão que privilegia a integração de pesquisas desenvolvidas no escopo regional de Bahia e Sergipe, em interação e debate com as demais pesquisas da pauta de agenda nacional dos estudos sociolinguísticos.

Em 2011, o I Encontro abordou a relação entre a variação, a história e a educação e ocorreu na Universidade do Estado da Bahia, Campus I, no Centro de Pesquisa e Desenvolvimento Regional (CPEDR/UNEB).

Em 2012, o II Encontro teve como foco as diferentes vertentes dos estudos sociolinguísticos estudos da variação e da mudança e da sócio-história do português brasileiro, os sociofuncionalistas e os 
de base etnográfica, entre outras - e ocorreu no CPEDR/UNEB. Esta edição também se inseriu no Projeto Linguagem na Cidade (FAPESB).

Em 2013, o III Encontro, discutindo a pesquisa em Salvador, foi organizado por três instituições o PPGEL/UNEB, o Programa de Pós-Graduação em Estudos Linguísticos da Universidade Federal de Minas Gerais (POSLIN/UFMG) e o Programa de Pós-Graduação em Estudos Linguísticos da Universidade Estadual de Feira de Santana (PPGEL/UEFS) - e foi realizado na CPEDR/UNEB; passou, então, a se inserir no Projeto Linguagem, Sociedade e Discurso, uma parceria entre a UNEB e a UFMG.

Em 2014, o IV Encontro voltou a sua atenção para os diferentes olhares sobre o português brasileiro. Nessa versão, foi organizado por quatro instituições - o PPGEL/UNEB, o POSLIN/UFMG, o PPGEL/UEFS e a Universidade Federal de Sergipe (UFS) - e continuou vinculado ao Projeto Linguagem, Sociedade e Discurso.

Em 2015, o V Encontro promoveu uma reflexão sobre os diálogos entre Brasil e África. Nessa edição, adquiriu o status de evento itinerante já que, pela primeira vez, aconteceu fora da UNEB, mais precisamente, na Universidade Estadual de Feira de Santana (UEFS), tendo como presidente da comissão organizadora a professora Josane Moreira de Oliveira, da UEFS, em parceria com a UNEB e a UFS.

Em 2016, o VI Encontro debruçou-se sobre questões atinentes ao português no Nordeste: (para além) das fronteiras linguísticas; nesse ano, retornou à UNEB, mantendo a parceria com a UEFS e a UFS.

Em 2017, o VII Encontro, buscando incorporar uma discussão sob as perspectivas acadêmica e política, tratou de redes e contatos. Como evento itinerante, ocorreu na UFS, no Campus de São Cristóvão, tendo como presidente da comissão organizadora a professora Raquel Meister Ko. Freitag, da Universidade Federal de Sergipe.

A produção decorrente das edições do Encontro de Sociolinguística tem sido sistematicamente compilada e compartilhada, constituindo-se em rica fonte de estudos descritivos sobre as variedades linguísticas do português, em interface com as vertentes de pesquisa e de contato dialetal atinentes à realidade regional.

As contribuições dessa parceria de pesquisa (cf. LOPES; OLIVEIRA; PARCERO, 2017; LOPES; PARCERO; BULHÕES, 2016; LOPES; ARAUJO; FREITAG, 2018; FREITAG; LOPES; ARAUJO, 2018; SOBRAL; LOPES; RAMOS, 2015, LOPES, CARVALHO, PELLÓN, 2013; CARVALHO; GOMES, 2017; CARVALHO; ROCHA; PARCERO, 2011, dentre outras) propiciam o conhecimento acerca de variedades do português brasileiro circunscritas a um espaço geográfico e social peculiar, o que se torna essencial como subsídio ao ensino de língua materna, o que é especialmente relevante no cenário educacional brasileiro, com a Base Nacional Comum Curricular (BNCC) e a diversidade no currículo (FREITAG, 2017).

A diretriz curricular da BNCC torna ainda mais relevante e premente a realização e a difusão de estudos sociolinguísticos que consideram as peculiaridades regionais, a fim de contribuir para o componente diversificado com caracterizações sociolinguísticas de comunidades de fala, especialmente aquelas distantes dos grandes centros e, por tabela, distantes dos polos produtores dos livros didáticos distribuídos em nível nacional após avaliação do Programa Nacional do Livro Didático (PNLD).

Assim, considerando o cenário de mudança de diretrizes curriculares, com a aprovação da BNNC do ensino fundamental e do ensino médio, na edição de 2018, o VIII Encontro de Sociolinguística retomou o tema da variação e ensino, agora agregando-o às crenças e atitudes linguísticas e à variação espacial; 
nesse último caso, estabeleceu um diálogo com a dialetologia, mais especificamente, com as pesquisas com os dados do ALiB, no que tem sido designado de trabalhos geossociolinguísticos.

Neste Número Especial da Tabuleiro de Letras, sistematizamos as colaborações do VIII Encontro de Sociolinguística, de modo a difundir e contribuir para o empreendimento educacional brasileiro, divididas em três partes:

1. Variação e ensino;

2. Crenças, atitudes e variação linguística.

3. A variação social e espacial nos dados do ALiB e de outros corpora.

A parte 1, Variação e Ensino, apresenta seis artigos de autores de cinco instituições diferentes. Em O que toda professora e todo professor de português precisam saber, Luciano Amaral Oliveira, da Universidade Federal da Bahia (UFBA), discute questões teóricas importantes para docentes de língua portuguesa, as quais partem da seguinte assertiva: não existem práticas pedagógicas sem teorias. Silvia Rodrigues Vieira, da UFRJ, com o artigo $A$ unidade e a diversidade no ensino de Língua Portuguesa, trata da questão da(s) norma(s) linguística(s) nas salas de aula de língua portuguesa. Com o artigo Conhecimento (socio)linguístico, livro didático e ensino de português, Cristina dos Santos Carvalho, da UNEB, examina imprecisões conceituais e inadequações procedimentais concernentes ao tratamento da variação linguística no livro didático de português e busca fazer uma reflexão sobre os conhecimentos (socio) linguísticos necessários ao professor de língua materna. Em Variação diacrônica e ensino, Fabrício da Silva Amorim, do Instituto Federal da Bahia (IFBA), convida o leitor a refletir sobre a (in)visibilidade da variação diacrônica no ensino de língua portuguesa a partir de algumas questões atinentes à relação entre os processos de variação e mudança linguísticas e o seu ensino na disciplina de língua portuguesa e no livro didático do nível médio. Em Manuais para o ensino elementar na Bahia: recortes históricos, Emília Helena Portella Monteiro de Souza, da UFBA, com o propósito de tornar evidentes os gêneros escolares de maior uso, trata de manuais usados com fins pedagógicos, do século XVI ao XIX, com enfoque no século XIX, na Bahia e ressalta os processos de leitura, que vigoraram nesse período. Silvana Silva de Farias Araújo e Nilton Carlos Carmo Sousa, da UEFS, com o artigo $A$ história social do português do Brasil e 0 preconceito linguístico, fazem uma reflexão sobre questões sócio-históricas que estão na base da formação e da caracterização atual do português do Brasil (PB), a exemplo dos contatos linguísticos e dos processos tardios de urbanização e de escolarização.

A parte 2, Crenças, atitudes e variação linguística, contém artigos de autores de três instituições diferentes. Andréia Silva Araújo e Damiana Karina Vieira Borges, da UFS, no artigo Atitudes linguísticas de estudantes universitários: o fenômeno da monotongação em foco, objetivam identificar as crenças e as atitudes linguísticas de 60 estudantes da Universidade Federal de Sergipe, perante o fenômeno da monotongação de ditongos decrescentes e crescentes do português. Em Percepção da palatalização do /S/ em coda: atitudes linguísticas de universitários, Josilene de Jesus Mendonça e Cósmia Karine Vieira Borges, da UFS, analisam a percepção e a avaliação de universitários da Universidade Federal de Sergipe em relação à palatalização do /S/ em coda silábica. Em Atitudes linguísticas de universitários em relação às formas pronominais a gente e tu, Andréia Silva Araújo e Josilene de Jesus Mendonça, da UFS, objetivam identificar as atitudes linguísticas de estudantes universitários frente ao uso da forma pronominal de $1^{\mathrm{a}}$ pessoa do plural a gente e da forma de $2^{\mathrm{a}}$ pessoa do singular $\mathbf{t u}$, bem como se elas (atitudes linguísticas) se assemelham ou não. Daisy Cordeiro e Lúcia Maria de Jesus Parcero, da UNEB, no 
artigo intitulado "É bom a gente aprendê mais, falá melhó": crenças e atitudes linguísticas dos sambadores e sambadeiras de roda do grupo Samba Chula de São Braz, examinam a relação das atitudes linguísticas dos sambadores e das sambadeiras do grupo Samba Chula de São Braz com o ensino da norma padrão da Língua Portuguesa e com a percepção das variedades do português brasileiro. No artigo Que língua é essa? Crenças, atitudes e identidade na fala do aprendiz brasileiro de inglês, Letícia Telles da Cruz propõe uma discussão a respeito da formação da identidade de aprendizes brasileiros de língua inglesa, tomando por base os estudos sobre diversidade linguística, letramento, crenças e formação docente, através do diálogo entre diferentes áreas que estudam a linguagem, como a Linguística Aplicada e a Linguística Teórica.

A Parte 3, A variação social e espacial nos dados do ALiB e de outros corpora, contém quatro textos de pesquisadores de duas instituições diferentes. No artigo $A$ variação lexical para peças do vestuário íntimo em um recorte do Projeto ALiB, Maria Bethânia Gomes Paes e Marcela Moura Torres Paim, da UFBA, fazem o levantamento das denominações para vestuário íntimo usadas por falantes de cinco pontos distribuídos entre os Estados de Alagoas e Sergipe com base no corpus do Projeto Atlas Linguístico do Brasil (ALiB) nos referidos pontos do Nordeste do Brasil. Em Gude: a produtividade das variantes lexicais dos grupos ciganos e não-ciganos da Bahia e de Pernambuco, Geysa Andrade da Silva e Silvana Soares Costa Ribeiro, da UFBA, analisam respostas fornecidas por falantes de etnia cigana dos estados da Bahia e de Pernambuco, em Silva (2017) no que se refere às designações para "bolinha de gude", comparando-as com as fornecidas por falantes não-ciganos estudados por Ribeiro (2012), com objetivo de examinarem se, na seleção lexical feita pelos entrevistados, há influência de fatores diatópicos, diassexuais e diageracionais. Tassila Ferreira Vale Guimarães e Norma da Silva Lopes, da UNEB, no artigo A indeterminação do sujeito na Bahia: a contribuição do ALIB para o ensino, apresentam um estudo que se situa entre a dialetologia e a sociolinguística sobre a variação social e espacial da indeterminação do sujeito no estado da Bahia. A partir de dados coletados do ALiB em sete mesorregiões da Bahia, observam condicionamentos sociais e espaciais para a escolha de variantes gramaticais, pronominais e nominais de indeterminação do sujeito. No artigo $A$ importância do Atlas linguístico do Brasil para o ensino de português, Josane Moreira de Oliveira, Marcela Moura Torres Paim e Silvana Soares Costa Ribeiro, a primeira da UEFS e as duas últimas da UFBA, tratam da importância dos atlas linguísticos para o ensino, destacando a publicação do Atlas linguístico do Brasil, que, entre outros, possui os seguintes objetivos: oferecer subsídios para o aprimoramento do ensino/aprendizagem de língua portuguesa e para uma melhor interpretação do caráter multidialetal do Brasil; e proporcionar aos interessados, sobretudo aos professores, nos estudos linguísticos um considerável volume de dados que permita aprofundar o conhecimento da realidade linguística do português brasileiro.

Com a organização de mais este Encontro de Sociolinguística, e com este Número Especial da Tabuleiro de Letras, registramos a nossa contribuição para a interlocução não só entre os participantes acadêmicos, mas também com os professores da Educação Básica, com uma produção científica relevante para uma pedagogia culturalmente sensível.

\section{Referências}


ALKMIN, T. Sociolinguística: parte I. In: MUSSALIN, Fernanda; BENTES, Ana Christina. (orgs.) Introdução à Linguística. Campinas: Pontes, 2000. p. 21-47.

BORTONI-RICARDO, S. M. Educação em língua materna: a sociolinguística na sala de aula. São Paulo: Parábola, 2004. 108 p.

BORTONI-RICARDO, S. M. Manual de sociolinguística. São Paulo: Contexto, 2017. 189 p.

BORTONI-RICARDO, S. M. Nós cheguemu na escola, e agora? sociolinguística e educação. São Paulo: Parábola: 2005. $263 \mathrm{p}$.

BRIGHT, W. As dimensões da Sociolinguística. In: FONSECA, M. S. V.; NEVES, M. Facure (orgs.), Sociolinguística. Rio de Janeiro: Eldorado, 1974.

CARVALHO, C. S.; GOMES, J. C. C.. OLHA, OLHE e OH: gramaticalização do verbo OLHAR na fala popular soteropolitana. Estudos linguísticos e literários, v. 57, p. 297-318, 2017.

CARVALHO, C. S.; ROCHA, F. A. B.; PARCERO, L. M. J. Discurso e cultura: diálogos interdisciplinares. Salvador: EDUNEB, 2011.

COELHO, I. L. et al. Para conhecer sociolinguística. São Paulo: Contexto, 2018. 174 p. (Coleção Para Conhecer Linguística)

FREITAG, R. M. K; LOPES, N. S.; ARAÚJO, S. S. F. Ampliando as redes, fortalecendo os contatos. A Cor das Letras, v. 19, n. 4Especial, p. 5-11, 2018.

FREITAG, R. M. K. A mudança linguística, a gramática e a escola. PerCursos, v. 18, n. 37, p. 63-91, 2017.

LABOV, W. Padrões sociolinguísticos. Trad. de Marcos Bagno, Maria Marta Pereira Scherre e Caroline Rodrigues Cardoso. São Paulo: Parábola, 2008 [1972]. 389 p.

LOPES, N. S.; ARAUJO, S. S. F.; FREITAG, R. M. K. A fala nordestina: entre a sociolinguística e a dialetologia. São Paulo: Blucher, 2016.

LOPES, N. S.; BULHOES, L. P.; PARCERO, L. M. J. Estudos da diversidade linguística. Salvador: EDUNEB, 2016.

LOPES, N. S.; OLIVEIRA, J. M.; PARCERO, L. M. J. Estudos sobre o português do Nordeste: língua, lugar e sociedade. São Paulo: Blucher, 2017.

LOPES, N. S.; PELLÓN, L. CARVALHO, C. S. Sociolinguística: estudos da variação, da mudança e da sócio-história do português brasileiro, sociolinguística paramétrica, sociofuncionalismo. Salvador: EDUNEB, 2013.

MARTINS, M. A.; ABRAÇADO, J. Apresentação. In: MARTINS, M. A.; ABRAÇADO, J. (Orgs.). Mapeamento sociolinguístico do Português Brasileiro. São Paulo: Contexto, 2014. p. 7-8.

MARTINS, M.; VIEIRA, S. R; TAVARES, A. Apresentação. In: MARTINS, M.; VIEIRA, S. R; TAVARES, A. (Orgs.). Ensino de Português e Sociolinguística. São Paulo: Contexto, 2014. p. 7-8.

MOLLICA, M. C. Fundamentação teórica: conceituação e delimitação. In: MOLLICA, M. C.; BRAGA, M. L. (Orgs.). Introdução à sociolinguística: o tratamento da variação. São Paulo: Contexto, 2004.

MOLLICA, M. C.; FERRAREZI JUNIOR, C. Apresentação. In: MOLLICA, M. C.; FERRAREZI JUNIOR, C. (Orgs.). Sociolinguística, sociolinguísticas: uma introdução. São Paulo: Contexto, 2016. p. 9-11,

SOBRAL, G. N.; LOPES, N. S.; RAMOS, J. Linguagem, sociedade e discurso. São Paulo: Blücher, 2015.

SOBRAL, G.; LOPES, N. S. A Bahia em perspectivas diversas. Salvador: Quarteto, 2015.

WEINREICH, U.; LABOV, W.; HERZOG, M. I. Fundamentos empíricos para uma teoria da mudança. Trad. de Marcos Bagno. São Paulo: Parábola, 2006 [1968]. 